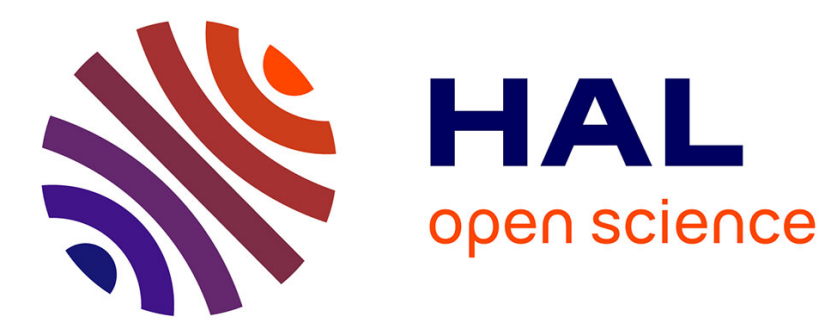

\title{
Acute respiratory distress syndrome mimickers lacking common risk factors of the Berlin definition
}

\author{
Aude Gibelin, Antoine Parrot, Bernard Maitre, Christian Brun-Buisson,
} Armand Mekontso Dessap, Muriel Fartoukh, Nicolas de Prost

\section{To cite this version:}

Aude Gibelin, Antoine Parrot, Bernard Maitre, Christian Brun-Buisson, Armand Mekontso Dessap, et al. Acute respiratory distress syndrome mimickers lacking common risk factors of the Berlin definition. Intensive Care Medicine, 2016, 42 (2), pp.164-172. 10.1007/s00134-015-4064-y . hal-01288664

\section{HAL Id: hal-01288664 https://hal.sorbonne-universite.fr/hal-01288664}

Submitted on 15 Mar 2016

HAL is a multi-disciplinary open access archive for the deposit and dissemination of scientific research documents, whether they are published or not. The documents may come from teaching and research institutions in France or abroad, or from public or private research centers.
L'archive ouverte pluridisciplinaire HAL, est destinée au dépôt et à la diffusion de documents scientifiques de niveau recherche, publiés ou non, émanant des établissements d'enseignement et de recherche français ou étrangers, des laboratoires publics ou privés. 
Acute respiratory distress syndrome mimickers lacking common risk factors of the

\section{Berlin definition}

\section{Running title: ARDS lacking risk factors of the Berlin definition}

Aude Gibelin ${ }^{1}$, MD, Antoine Parrot ${ }^{1}, \mathrm{MD}$, Bernard Maitre ${ }^{2}, \mathrm{MD}, \mathrm{PhD}$, Christian BrunBuisson $^{3,4}, \mathrm{MD}$, Armand Mekontso Dessap ${ }^{3,4}, \mathrm{MD}, \mathrm{PhD}$, Muriel Fartoukh ${ }^{1,4} *, \mathrm{MD}, \mathrm{PhD}$, and Nicolas de Prost ${ }^{3,4} * \mathrm{MD}, \mathrm{PhD}$

* MF and NDP contributed equally to this work

${ }^{1}$ Assistance Publique-Hôpitaux de Paris, Hôpital Tenon, Unité de Réanimation médicochirurgicale, Pôle Thorax Voies aériennes, Groupe hospitalier des Hôpitaux Universitaires de l'Est Parisien, Paris, France \& Sorbonne Universités, UPMC Univ Paris 06; ${ }^{2}$ Assistance Publique-Hôpitaux de Paris, CHU Henri Mondor, DHU A-TVB, Service de Réanimation Médicale, Antenne de Pneumologie, Créteil, F-94010 France; ${ }^{3}$ Assistance PubliqueHôpitaux de Paris, CHU Henri Mondor, DHU A-TVB, Service de Réanimation Médicale, Créteil, F-94010 France ; ${ }^{4}$ Université Paris Est Créteil, Faculté de Médecine de Créteil, Groupe de Recherche Clinique CARMAS, Créteil, F-94010, France

\section{Corresponding author:}

Dr Muriel FARTOUKH

Assistance Publique-Hôpitaux de Paris, Hôpital Tenon, Service de Réanimation MédicoChirurgicale, F-75970, Paris, France; Sorbonne Universités, UPMC Univ Paris 06, Paris, France; Collégium Gallilée, Groupe de Recherche Clinique CARMAS (CArdiovascular and 
Respiratory Manifestations of Acute lung injury and Sepsis), Université Paris Est Créteil, Faculté de Médecine de Créteil, Créteil, F-94010, France.

Email: muriel.fartoukh@tnn.aphp.fr

Phone: + 3356016574

Conflict of interest statement: none of the authors have conflicts of interest 


\section{ABSTRACT}

Purpose: Some patients presenting with acute respiratory failure and meeting the Berlin criteria for the acute respiratory distress syndrome (ARDS) lack exposure to common risk factors (CRF). These so-called 'ARDS mimickers' often lack histological diffuse alveolar damage. We aimed to describe such ARDS mimickers lacking CRF (ARDS ${ }_{\mathrm{CRF}}$ ), in comparison with others (ARDS $\left.\mathrm{CRF}_{+}\right)$.

Methods: Retrospective study including all patients receiving invasive mechanical ventilation for ARDS admitted to the intensive care units of two tertiary care centers from January 2003 to December 2012.

Results: The prevalence of $\mathrm{ARDS}_{\mathrm{CRF}}$ was $7.5 \%$ (95\% CI [5.5-9.5]; $\left.\mathrm{n}=50 / 665\right)$. Based on medical history, broncho-alveolar lavage fluid cytology and chest CT scan patterns, four etiological categories were identified: immune $(n=18 ; 36 \%)$, drug-induced $(n=13 ; 26 \%)$, malignant $(n=7 ; 14 \%)$, and idiopathic $(n=12 ; 24 \%)$. Although the ARDS $_{\text {CRF- }}$ patients had a lower logistic organ dysfunction score (4 [3-8] vs. 10 [6-13]; p<0.0001) and less often shock upon ICU admission (44\% vs. 80\%; p<0.0001) than their counterparts, their overall ICU mortality rate was very high (66\% [46-74]), and the absence of CRF remained associated with ICU mortality by multivariable logistic regression analysis (adjusted OR=2.06; 95\% CI [1.02-4.18]; $\mathrm{p}=0.044)$. Among $\mathrm{ARDS}_{\mathrm{CRF}}$ patients, the presence of potentially reversible lung lesions with corticosteroids $(\mathrm{aOR}=0.14 ; 95 \% \mathrm{CI}[0.03-0.62])$ was associated with ICU survival.

Conclusions: The absence of CRF among patients with ARDS is common, and is associated with a higher risk of mortality. For such "atypical" ARDS, a complete diagnostic workup, including broncho-alveolar lavage fluid cytology and chest CT scan patterns should be 
performed to identify those patients who might benefit from specific therapies, including corticosteroids.

Key words: Respiratory Distress Syndrome, Adult; Respiration, Artificial; Pulmonary edema; Lung Diseases; Interstitial; Idiopathic Pulmonary Fibrosis 


\section{INTRODUCTION}

The recent Berlin definition of the acute respiratory distress syndrome (ARDS) [1] stipulates that respiratory symptoms are to occur (or worsen) within seven days after exposure to at least one "common" ARDS risk factor (CRF), classified as direct (e.g., pneumonia, gastric aspiration...) or indirect (e.g., extra-pulmonary sepsis, polytrauma, pancreatitis...). Still, the members of the ARDS Definition Task Force anticipated that a subset of patients would have the clinical and radiological features of ARDS, while not having been exposed to any of these CRFs, and stated that an "objective assessment" of left heart filling pressures would then be required to rule out a pulmonary edema of the hydrostatic type.[1]

On the other hand, it is apparent that ARDS criteria encompass a widely heterogeneous group of pathologic processes. Indeed, none of the proposed definitions of ARDS, $[2,3]$ including the recent Berlin definition,[1] appears to be fully reliable for diagnosing diffuse alveolar damage (DAD), the commonly accepted pathological hallmark of ARDS.[3] Indeed, other lesions than DAD have been reported in more than one third of autopsied cases, including infectious pneumonia without $\mathrm{DAD}$, lung fibrosis either associated with an auto-immune disease or drug-induced, organizing pneumonia, diffuse alveolar hemorrhage, lung tumoral infiltration, acute pulmonary edema, pulmonary embolism, or even the lack of histological abnormality.[4] These unusual histological entities, commonly occurring in the absence of the CRFs for ARDS, have been previously termed "imitators of ARDS".[5, 6] The prevalence and the prognosis of patients fulfilling the Berlin criteria for ARDS while having no CRF have, to the best of our knowledge, not been previously assessed. The primary objective of this study was to report the prevalence and etiologies of patients developing ARDS despite no exposure to any of the "common" risk factors and to contrast their clinical presentation and outcomes with those of their counterparts. The secondary objective was to assess in the 
subgroup of patients with ARDS and no CRF the impact on outcomes of the presence of lung lesions potentially responding to therapy with corticosteroids.

\section{METHODS}

Methods are further described in the online supplement.

\section{Study design}

We conducted a retrospective study including all consecutive patients presenting with ARDS [1] within 48 hours of admission to the intensive care units (ICUs) of two tertiary care centers (Hôpital Tenon, Paris and Hôpital Henri Mondor, Créteil, France) from January 2003 to December 2012. This observational, non-interventional analysis of medical records was approved by the Institutional Review Board of the French society for respiratory medicine. As per French law, no informed consent is required for this type of study.

\section{Subjects, data collection and definitions}

Patients were included in the cohort when aged 18 years or older and having received invasive mechanical ventilation for management of ARDS. Exclusion criteria were: previously known lung interstitial disease or tumoral infiltration; ARDS due to negative pressure pulmonary edema; left heart failure in the absence of identified CRF; mild ARDS treated with noninvasive ventilation only. ARDS was categorized as mild, moderate, or severe according to the Berlin definition.[1] A particular attention was paid to the timing criteria of the Berlin definition; as per definition, for patients not exposed to ARDS CRF, the onset of ARDS was to occur within one week of new or worsening respiratory symptoms.[1] ARDS patients were also classified into two groups, whether they had been exposed to any "common" risk factor 
$\left(\mathrm{ARDS}_{\mathrm{CRF}+}\right)$ or not $\left(\mathrm{ARDS}_{\mathrm{CRF}-}\right)$ (online supplement, Table 1). Patients with "vasculitides" were deemed to have ARDS with no CRF because vasculitides are not pathologically characterized by diffuse alveolar damage. Increase in left heart filling pressures was ruled out using transthoracic and/or trans-esophageal echocardiography in all $\mathrm{ARDS}_{\mathrm{CRF}}$ patients. The ARDS $_{\mathrm{CRF}}$ patients were then separated into four etiological groups, as follows: 1) immune $A R D S$, including vasculitides, as defined by the American College of Rheumatology (ACR) criteria,[7] and connective tissue diseases according to ACR and American Rheumatogical Association (ARA) criteria; 2) drug-induced ARDS, defined by previous exposure to a drug known as a pneumonia inducer in the absence of any other risk factor for ARDS (i.e., "definite or probable" drug-induced ARDS);[8] 3) malignant ARDS, which required cytological or pathological evidence of hematologic or solid malignancy; and 4) idiopathic $A R D S$, defined by the absence of both CRFs and the above etiologies despite a comprehensive etiological work-up.

Demographics, clinical and laboratory variables upon ICU admission, at 48 hours, and during ICU stay were abstracted from the medical charts of all patients. Their initial severity was assessed using the SAPS II (Simplified Acute Physiology II)[9] and LOD (Logistic Organ Dysfunction) scores.[10] Outcome variables included the use of adjuvant therapies for ARDS (i.e., neuromuscular blocking agents, nitric oxide inhalation, prone positioning, extracorporeal membrane oxygenation), the need for haemodialysis or vasopressors, the administration of corticosteroids, the number of ventilator-free days at day 28 , and ICU mortality.

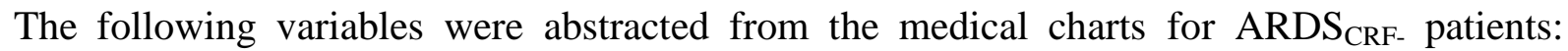
presence of extra-pulmonary symptoms on ICU admission, broncho-alveolar lavage (BAL) fluid cytological analysis, chest CT scan patterns, and auto-immunity tests. Chest CT scan lesions were analysed and described by a radiologist according to the Fleischner Society Glossary of Terms for Thoracic Imaging.[11] The presence of lung lesions potentially 
responding to therapy with corticosteroids was assessed by three experts blinded to the final diagnosis and outcome, based on BAL fluid cytology and chest CT scan patterns, and patients were considered as "potential responders" when an agreement of all three experts was met.[12-14]

\section{Data presentation and statistical analysis}

Continuous variables are reported as median $\left[25^{\text {th }}-75^{\text {th }}\right.$ percentiles $]$ or mean $( \pm$ standard deviation, SD) and compared as appropriate. Categorical variables are reported as number and percentages [95\% confidence interval] and compared as appropriate. Factors associated with ICU mortality were determined by univariable and multivariable backward logistic regression analyses, both within the whole cohort of patients (i.e., $\mathrm{ARDS}_{\mathrm{CRF}+}$ and $\mathrm{ARDS}_{\mathrm{CRF}}$ patients), and within the $\mathrm{ARDS}_{\mathrm{CRF}}$ group. Independent variables with $\mathrm{p}<0.10$ in univariable analysis were included in the multivariable analysis, with backward elimination of variables displaying a $\mathrm{p}$ value $>0.05$. Interaction between variables were assessed using the Mantel-Haenszel test and interaction terms introduced in the model as appropriate. Analyses were conducted using the SPSS Base 21.0 statistical software package (SPSS Inc., Chicago, IL).

\section{RESULTS}

\section{Prevalence of ARDS with no common risk factors}

Over the ten-year study period, 812 patients were hospitalized for suspected ARDS in the two ICUs, of whom 110 had non-inclusion criteria, 37 received non-invasive ventilation only and 665 remained in the study cohort (Figure 1). In this large cohort, the prevalence of ARDS with no CRF $(n=50)$ was $7.5 \%$ [5.5-9.5]. 
$\operatorname{ARDS}_{\mathrm{CRF}+}$ patients $(\mathrm{n}=615)$ had been exposed to the following risk factors: pneumonia $(n=310 ; 50.4 \%[46.0-54.0])$, aspiration of gastric content $(n=214 ; 34.8 \%$ [31.2-38.8]), nonpulmonary sepsis $(\mathrm{n}=150 ; 24.4 \%[20.6-27.4])$, non-cardiogenic shock $(\mathrm{n}=114 ; 18.5 \%$ [15.021.0]), multiple transfusions $(n=27 ; 4.4 \%$ [2.5-5.5]), drug overdose $(n=18 ; 2.9 \%$ [1.7-4.3]), pulmonary contusion $(n=8 ; 1.3 \%[0.2-1.8])$, pancreatitis $(n=7 ; 1.1 \%[0.2-1.8])$, smoke inhalation $(\mathrm{n}=2 ; 0.3 \%[0.0-0.7])$, and near-drowning $(\mathrm{n}=1 ; 0.2 \%[0.0-0.6])$.

\section{Outcome of patients with and without common risk factors for ARDS}

As compared with ARDS $_{\mathrm{CRF}+}$ patients, $\mathrm{ARDS}_{\mathrm{CRF}}$ patients showed a longer time from respiratory symptoms onset to ICU admission, were more frequently referred to the ICU for acute respiratory failure, had lower severity scores upon ICU admission and less shock (Table 1). Overall, 360 patients $(54.1 \%$ [50.1-57.9]) died in the ICU. There was a trend toward a higher ICU mortality rate in $\mathrm{ARDS}_{\mathrm{CRF}}$ patients, as compared with their counterparts $(66.0 \%$ [52.9-79.1] vs. 53.2\% [49.1-56.9]; $\mathrm{p}=0.09$ ). Among variables available within 48 hours of ICU admission, the absence of common risk factors for ARDS was associated with ICU mortality (adjusted OR, aOR=2.06; 95\% CI [1.02-4.18]) after adjusting on covariates significantly associated with mortality (online supplement, Table 2).

\section{Etiologies and outcomes of ARDS patients with no common risk factors}

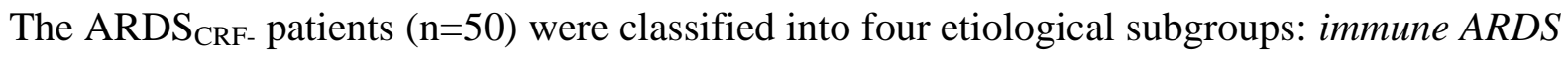
$(\mathrm{n}=18 ; 36 \%$ [23-49]), drug-induced ARDS ( $\mathrm{n}=13 ; 26 \%$ [14-38]), malignant ARDS $(\mathrm{n}=7 ; 14 \%$ [4-24]), and idiopathic ARDS ( $\mathrm{n}=12 ; 24 \%$ [12-36]) (Table 2). When available, histopathological examination of lung tissue samples $(n=12)$ revealed the presence of DAD $(n=4)$, organizing pneumonia $(n=3)$, haemophagocytosis $(n=1)$, or cancer $(n=4)$ (online supplement, Table 3). 
The ICU mortality of $\mathrm{ARDS}_{\mathrm{CRF}}$ - patients was 66\% [46-74] and did not differ significantly according to the four etiological subgroups (immune ARDS: 50\% [36-64]; drug-induced ARDS: 69\% [56-82]; malignant ARDS: 96\% [91-100]; idiopathic ARDS: 75\% [63-87]; $\mathrm{p}=0.29)$. Corticosteroids were initiated in $100 \%$ of the ICU survivors, as compared with $76 \%$ of the non-survivors (Table 3). The median duration of mechanical ventilation before corticosteroid treatment initiation was 2 [1-3] days. A predominantly hemorrhagic or lymphocytic BAL fluid cytology, as opposed to a macrophagic or neutrophilic one, was associated with survival of $\mathrm{ARDS}_{\mathrm{CRF}}$ patients (Table 3). The presence of positive ANCA tests and of a plasma creatinine level > $140 \mu \mathrm{mol} / \mathrm{L}$ were also associated with survival, consistent with the fact that patients with vasculitides exhibited a better survival than those with connective tissue diseases (1/6 vs. 8/11 died; $\mathrm{p}=0.049)$. Conversely, chest CT scan abnormalities suggestive of pulmonary fibrosis tended to be associated with ICU mortality (Table 3). The three experts' consensus considered "potentially reversible lung lesions" to be present in 19 patients (38\%); in multivariable analysis (Table 4), this composite variable was a protective factor for ICU mortality $(\mathrm{aOR}=0.14$; 95\% CI [0.03-0.62]). The presence of potentially reversible lung lesions was mainly associated with the presence of a lymphocytic BAL fluid, with a threshold value of lymphocyte counts $>20 \%$, together with the lack of signs consistent with pulmonary fibrosis (honeycombing and traction bronchiectasis) on chest CT scan (online supplement, Figures 1 and 2).

\section{DISCUSSION}

This study is, to the best of our knowledge, the first to report the prevalence, characteristics, management and outcomes of patients meeting the radiological and clinical criteria of the 
Berlin definition of ARDS while having none of the common risk factors listed. The main results are as follows: 1) the prevalence of ARDS with no CRF was $7.5 \%$ among a large cohort of ARDS patients requiring invasive mechanical ventilation; 2) the absence of CRF for ARDS was an independent risk factor of ICU mortality; and 3) among ARDS $\mathrm{CRF}_{\text {- }}$ patients, the presence of a lung cellular inflammatory infiltration, assessed by both BAL fluid cytology and chest CT scan patterns, suggesting the potential reversibility of lung lesions with antiinflammatory agents, was an independent predictor of survival.

\section{Prevalence and etiologies of ARDS with no common risk factors of the Berlin definition}

Our series shows that ARDS with no CRF is a frequent and peculiar condition among unselected patients with ARDS, with a prevalence of $7.5 \%$. This prevalence may however have been overestimated because our study was conducted in only two centers, one of which houses a specialized thoracic center, where the prevalence was higher than in the other. Nevertheless, our results are consistent with previous series including selected ARDS cases and reporting a high prevalence of lung histology other than DAD.[15-17] Furthermore, that both clinical and radiological definitions of ARDS correlate imperfectly with histological DAD lesions has been previously emphasized from autopsy,[15] as well as lung biopsy series of ARDS.[18] Indeed, Thille et al. recently showed that 9\% of 356 patients who had died of ARDS while meeting the Berlin criteria had various pathologic features, including fibrosis, alveolar hemorrhage, or lung tumor infiltration.[15] Histological analyses from selected patients who underwent surgical lung biopsies showed even more striking results, with $60 \%$ exhibiting other lesions than DAD. [16]

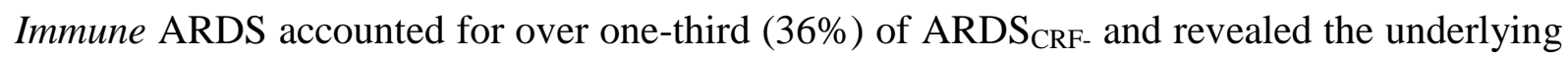
immune disease in most cases, consistent with the fact that patients having acute exacerbations of previously known interstitial lung diseases were excluded a priori. Drug- 
induced ARDS was the second most frequent etiology, with a predominance of chemotherapy agents incriminated. Although we may have underestimated the relative importance of this etiology by considering only cases of "probable" drug-induced ARDS (i.e., no established factors for ARDS except for the specific drug exposure within one year).[8], the overall frequency recorded in our series $(2.8 \%)$ is consistent with that recently estimated by Dhokarh et al.[8] among patients with acute lung injury (3\%). Malignant ARDS represented 14\% of

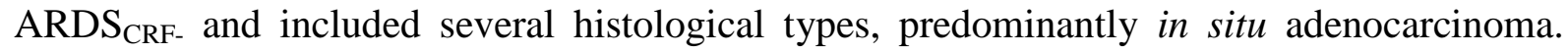
Finally, and although lung pathology had been obtained only for a limited number of patients, idiopathic ARDS (24\%) likely encompassed patients with acute interstitial pneumonia (DAD lesions were confirmed in 2/4 patients with idiopathic ARDS), a rare entity that was initially described as a clinical and radiological ARDS[19] with histological DAD lesions developing in spite of no exposure to any ARDS risk factor, and exhibiting a high mortality rate.[20]

\section{Outcomes of patients having ARDS with no common risk factors}

Albeit consistent with the median SAPS II value on admission, the in-ICU mortality of the whole cohort (54\%) was notably higher than that reported in ARDS trials, ranging from 27\% in mild to $45 \%$ in severe ARDS,[1] likely related to differences in the case mix, with unselected and sicker patients being included in our observational study. In fact, the ICU mortality in our study was in the range of what has recently been reported in a series of ARDS patients with cancer in the 2006-2011 period (52\%).[21] Nevertheless, our results suggest that $\mathrm{ARDS}_{\mathrm{CRF}}$ patients may have a poorer prognosis than their counterparts. Indeed, the absence of CRF remained associated with ICU mortality after adjustment for the severity scores, age, the severity of ARDS and shock, and the absence of bacterial infection. Of note, the prolonged use of non-invasive ventilation was also independently associated with mortality, in line with previous series suggesting its potentially harmful effects in patients with de novo acute respiratory failure.[22] 
Early identification of $\mathrm{ARDS}_{\mathrm{CRF}}$ patients may improve their management and outcome. Importantly, the clinical presentation of $\mathrm{ARDS}_{\mathrm{CRF}}$ patients differed from that of other ARDS patients in several respects. First, $\mathrm{ARDS}_{\mathrm{CRF}}$ patients exhibited a longer time between the onset of respiratory symptoms and ICU admission, with a worsening of symptoms occurring within two days prior to ICU admission, consistent with the timing criterion of the Berlin definition.[1] Second, the presence of shock on ICU admission was less frequent, consistent with findings from other series.[23] Together with the lack of recognized risk factor for ARDS, these features should raise the suspicion for an unusual etiology, and drive the clinician to perform a comprehensive diagnostic work-up in search of etiologies potentially amenable to specific therapies.[6]

In the $\mathrm{ARDS}_{\mathrm{CRF}}$ group, ICU survival was associated with the presence of potentially reversible lung lesions, as assessed by three independent experts blinded to outcome, based on BAL cytology and chest CT scan patterns available within the first 48 hours of ICU admission. Altogether, these findings suggest that $\mathrm{ARDS}_{\mathrm{CRF}}$ patients, who exhibit a high mortality, may have better outcomes when cytological or radiological signs suggestive of lung lesions potentially responding to therapy with anti-inflammatory agents are present. Such findings are in line with observations in patients with idiopathic pulmonary fibrosis, where lung cellular infiltration scores, obtained from open lung biopsies, together with an "alveolar" pattern on chest CT scan (i.e., predominance of ground glass opacities) allow for predicting the response to a corticosteroid challenge.[12, 24] In contrast, in typical ARDS cases (i.e., $\left.\mathrm{ARDS}_{\mathrm{CRF}+}\right)$, BAL fluid cytological analyses usually show a predominance of neutrophils,[25] and chest CT scans most frequently reveal alveolar consolidations of lower lobes.[26] Last, as recently showed, the early acquisition of a chest CT scan allows for predicting a poor outcome when lung fibrosis is present.[27] Thus, both chest CT scans and BAL fluid analysis could be important decision making tools in this subgroup of $\mathrm{ARDS}_{\mathrm{CRF}}$ patients, as they 
might help identifying which patients are more likely to benefit from specific therapies, including corticosteroids.

Surprisingly, acute renal failure, as defined by a plasma creatinine level $>140 \mu \mathrm{mol} / \mathrm{L}$, was a protective factor for mortality, likely reflecting the fact that it was mainly associated with vasculitis, a condition associated with a low mortality (17\%) in the current study. However, the proportion of patients requiring hemodialysis during their ICU stay was not different between survivors and non-survivors of the $\mathrm{ARDS}_{\mathrm{CRF}}$ group.

\section{Limitations of the study}

Our study has several limitations. First, we used a two-center retrospective design, which may have caused a selection bias, thereby limiting the generalizability of our findings. Indeed, we cannot exclude that some of these patients categorized as having ARDS with no CRF and exhibiting a subacute presentation (i.e., longer than 7 days) have been misdiagnosed because previous respiratory symptoms could have been underestimated or neglected. Moreover, the etiologies of ARDS with no CRF could vary depending on hospital recruitment and size of the cohort. Second, important predictors of mortality related to mechanical ventilation (i.e., tidal volume, positive end-expiratory pressure level, plateau and driving pressure [28]) were not entered in the mortality analyses, because these parameters were not readily available due to the retrospective design and the ten-year span of the study. However, because patients included were admitted after the demonstration of a reduction in mortality with 'protective ventilation',[29] all patients of the current study received a standardized tidal volume of 6 $\mathrm{mL} / \mathrm{kg}$. Third, although meeting the Berlin criteria for mild ARDS if having a $\mathrm{PaO}_{2} / \mathrm{FiO}_{2}$ ratio $<300 \mathrm{mmHg}$, patients who received non-invasive ventilation only were not included in the study cohort because we assumed that, due to the retrospective design of the study, ARDS might have been less well identified and reported over the study period. As a matter of fact, 
only 37 patients (5\% of the whole cohort) were identified as having ARDS while receiving non-invasive ventilation only. This might be explained at least in part because patients from the current study were included between 2003 and 2012, i.e., before the Berlin definition was proposed, and thus ARDS was potentially underdiagnosed in this less severe subgroup of patients. Fourth, lung histopathological specimens were obtained in only $24 \%$ of our patients. The low number of lung biopsies $(n=5)$ probably reflects the concerns of intensivists regarding the risk associated with this procedure, although previous series have suggested that open lung biopsies may be well tolerated even in severe ARDS patients.[17, 30] Fifth, the small numbers of patients within each etiological $\mathrm{ARDS}_{\mathrm{CRF}}$ subgroup may have limited our ability to show differences among clinical or laboratory features, as well as in management and outcomes. Sixth, although vasculitides were mentioned among risk factors for ARDS in the Berlin definition, we have deliberately classified patients with vasculitides within the ARDS $_{\mathrm{CRF}}$ group. Indeed, lung involvement in vasculitides is not pathologically characterized by diffuse alveolar damage but rather by diffuse alveolar hemorrhage and capillaritis, so vasculitides are usually classified as ARDS mimickers rather than "common risk factor for ARDS". [5, 6, 16]

We believe our work has several important clinical implications. First, we report a meaningful prevalence of so-called ARDS "mimickers", having no CRF from the Berlin definition, a feature identified as an independent factor of mortality in a large cohort of unselected ARDS patients receiving invasive mechanical ventilation. Second, among the subset of ARDS $_{\mathrm{CRF}-}$ patients, BAL fluid cytology and chest CT scan might help identifying a subset of patients who might benefit from specific therapies and have a better outcome. Whether early therapy with anti-inflammatory agents could decrease the mortality of ARDS $_{\mathrm{CRF}}$ - patients and which patients would benefit most from this treatment need to be prospectively assessed. 


\section{ACKNOWLEDGEMENTS}

The authors thank Prof A. Tazi for his valuable insights and help in designing the study.

\section{CONFLICT OF INTEREST STATEMENT}

None of the authors have conflicts of interest 


\section{REFERENCES}

1. Ranieri VM, Rubenfeld GD, Thompson BT, et al. with ARDS Definition Task Force (2012) Acute respiratory distress syndrome: the Berlin Definition. JAMA J Am Med Assoc 307:2526-2533. doi: 10.1001/jama.2012.5669

2. Bernard GR, Artigas A, Brigham KL, et al. (1994) The American-European Consensus Conference on ARDS. Definitions, mechanisms, relevant outcomes, and clinical trial coordination. Am J Respir Crit Care Med 149:818-824. doi: 10.1164/ajrccm.149.3.7509706

3. Ferguson ND, Frutos-Vivar F, Esteban A, et al. (2005) Acute respiratory distress syndrome: underrecognition by clinicians and diagnostic accuracy of three clinical definitions. Crit Care Med 33:2228-2234.

4. Esteban A, Fernández-Segoviano P, Frutos-Vivar F, et al. (2004) Comparison of clinical criteria for the acute respiratory distress syndrome with autopsy findings. Ann Intern Med 141:440-445.

5. Schwarz MI, Albert RK (2004) "Imitators" of the ARDS: implications for diagnosis and treatment. Chest 125:1530-1535.

6. Guérin C, Thompson T, Brower R (2014) The ten diseases that look like ARDS. Intensive Care Med. doi: 10.1007/s00134-014-3608-x

7. Jennette JC, Falk RJ, Andrassy K, et al. (1994) Nomenclature of systemic vasculitides. Proposal of an international consensus conference. Arthritis Rheum 37:187-192.

8. Dhokarh R, Li G, Schmickl CN, et al. (2012) Drug-associated acute lung injury: a population-based cohort study. Chest 142:845-850. doi: 10.1378/chest.11-2103

9. Le Gall JR, Lemeshow S, Saulnier F (1993) A new Simplified Acute Physiology Score (SAPS II) based on a European/North American multicenter study. JAMA J Am Med Assoc 270:2957-2963.

10. Le Gall JR, Klar J, Lemeshow S, et al. (1996) The Logistic Organ Dysfunction system. A new way to assess organ dysfunction in the intensive care unit. ICU Scoring Group. JAMA J Am Med Assoc 276:802-810.

11. Hansell DM, Bankier AA, MacMahon H, et al. (2008) Fleischner Society: glossary of terms for thoracic imaging. Radiology 246:697-722. doi:

10.1148/radiol.2462070712

12. Gay SE, Kazerooni EA, Toews GB, et al. (1998) Idiopathic pulmonary fibrosis: predicting response to therapy and survival. Am J Respir Crit Care Med 157:10631072. doi: 10.1164/ajrccm.157.4.9703022 
13. Wells AU, Hansell DM, Rubens MB, et al. (1993) The predictive value of appearances on thin-section computed tomography in fibrosing alveolitis. Am Rev Respir Dis 148:1076-1082. doi: 10.1164/ajrccm/148.4_Pt_1.1076

14. Terriff BA, Kwan SY, Chan-Yeung MM, Müller NL (1992) Fibrosing alveolitis: chest radiography and CT as predictors of clinical and functional impairment at follow-up in 26 patients. Radiology 184:445-449. doi: 10.1148/radiology.184.2.1620845

15. Thille AW, Esteban A, Fernández-Segoviano P, et al. (2013) Comparison of the Berlin definition for acute respiratory distress syndrome with autopsy. Am J Respir Crit Care Med 187:761-767. doi: 10.1164/rccm.201211-19810C

16. Patel SR, Karmpaliotis D, Ayas NT, et al. (2004) The role of open-lung biopsy in ARDS. Chest 125:197-202.

17. Papazian L, Doddoli C, Chetaille B, et al. (2007) A contributive result of open-lung biopsy improves survival in acute respiratory distress syndrome patients. Crit Care Med 35:755-762. doi: 10.1097/01.CCM.0000257325.88144.30

18. Guerin C, Bayle F, Leray V, et al. (2015) Open lung biopsy in nonresolving ARDS frequently identifies diffuse alveolar damage regardless of the severity stage and may have implications for patient management. Intensive Care Med 41:222-230. doi: $10.1007 / \mathrm{s} 00134-014-3583-2$

19. Katzenstein AL, Myers JL, Mazur MT (1986) Acute interstitial pneumonia. A clinicopathologic, ultrastructural, and cell kinetic study. Am J Surg Pathol 10:256267.

20. Olson J, Colby TV, Elliott CG (1990) Hamman-Rich syndrome revisited. Mayo Clin Proc 65:1538-1548.

21. Azoulay E, Lemiale V, Mokart D, et al. (2014) Acute respiratory distress syndrome in patients with malignancies. Intensive Care Med 40:1106-1114. doi:

10.1007/s00134-014-3354-0

22. Carrillo A, Gonzalez-Diaz G, Ferrer M, et al. (2012) Non-invasive ventilation in community-acquired pneumonia and severe acute respiratory failure. Intensive Care Med 38:458-466. doi: 10.1007/s00134-012-2475-6

23. Guérin C, Reignier J, Richard J-C, et al., PROSEVA Study Group (2013) Prone positioning in severe acute respiratory distress syndrome. N Engl J Med 368:21592168. doi: 10.1056/NEJMoa1214103

24. Wells AU, Desai SR, Rubens MB, et al. (2003) Idiopathic pulmonary fibrosis: a composite physiologic index derived from disease extent observed by computed tomography. Am J Respir Crit Care Med 167:962-969. doi: 10.1164/rccm.2111053

25. Idell S, Cohen AB (1985) Bronchoalveolar lavage in patients with the adult respiratory distress syndrome. Clin Chest Med 6:459-471. 
26. Caironi P, Carlesso E, Gattinoni L (2006) Radiological imaging in acute lung injury and acute respiratory distress syndrome. Semin Respir Crit Care Med 27:404-415. doi: $10.1055 / s-2006-948294$

27. Zafrani L, Lemiale V, Lapidus N, et al. (2014) Acute respiratory failure in critically ill patients with interstitial lung disease. PloS One 9:e104897. doi:

10.1371/journal.pone.0104897

28. Amato MBP, Meade MO, Slutsky AS, et al. (2015) Driving pressure and survival in the acute respiratory distress syndrome. N Engl J Med 372:747-755. doi:

10.1056/NEJMsa1410639

29. (2000) Ventilation with lower tidal volumes as compared with traditional tidal volumes for acute lung injury and the acute respiratory distress syndrome. The Acute Respiratory Distress Syndrome Network. N Engl J Med 342:1301-1308. doi: 10.1056/NEJM200005043421801

30. Papazian L, Thomas P, Bregeon F, et al. (1998) Open-lung biopsy in patients with acute respiratory distress syndrome. Anesthesiology 88:935-944. 


\section{FIGURE LEGENDS}

Figure 1. Selection of the patients included in the study. Common risk factors (CRF) for the acute respiratory distress syndrome (ARDS) were adapted from the Berlin definition (1): pneumonia, gastric aspiration, pulmonary contusion, drowning, inhalation of gases, extra pulmonary sepsis, polytrauma, pancreatitis, burn, non-cardiogenic shock, drug intoxication, polytransfusion. VAP, ventilator-acquired pneumonia; ILD, interstitial lung disease; NPPE, negative pressure pulmonary edema; $\mathrm{CHF}$, congestive heart failure; NIV, non-invasive ventilation; $\mathrm{ARDS}_{\mathrm{CRF}+}$, patients having $\mathrm{ARDS}$ with $\mathrm{CRF}$; $\mathrm{ARDS}_{\mathrm{CRF}-}$, patients having ARDS with no CRF. 
Table 1. Characteristics of 665 ARDS patients upon admission and during ICU stay.

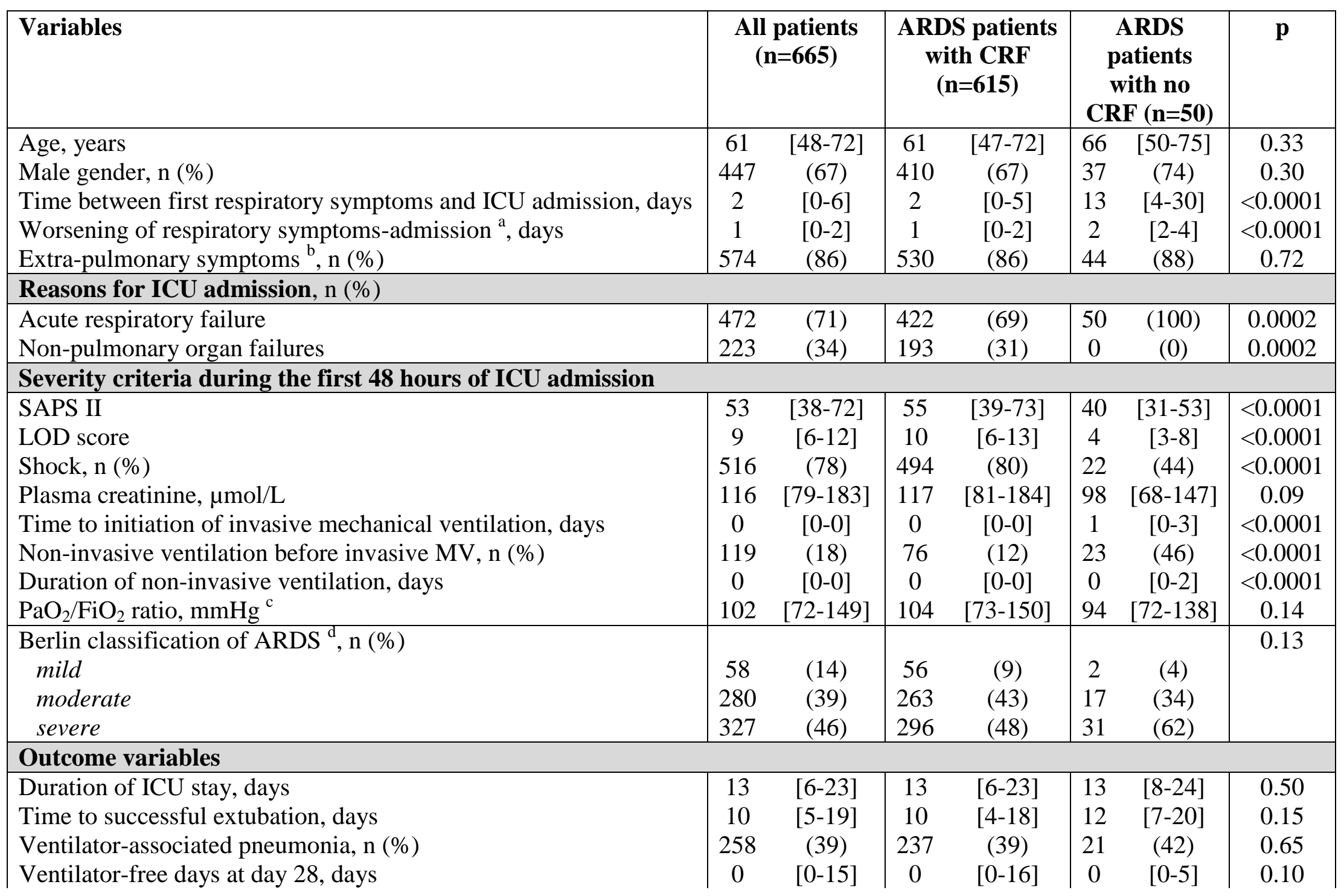




\begin{tabular}{|c|c|c|c|c|c|c|c|}
\hline $\begin{array}{l}\text { Ventilator-free days at day } 60 \text {, days } \\
\text { ICU Mortality, n (\%) }\end{array}$ & $\begin{array}{c}0 \\
360\end{array}$ & $\begin{array}{c}{[0-47]} \\
(54)\end{array}$ & $\begin{array}{c}0 \\
327\end{array}$ & $\begin{array}{c}{[0-47]} \\
(53)\end{array}$ & $\begin{array}{c}0 \\
33 \\
\end{array}$ & $\begin{array}{c}{[0-37]} \\
(66)\end{array}$ & $\begin{array}{l}0.059 \\
0.088\end{array}$ \\
\hline \multicolumn{8}{|c|}{ Rescue maneuvers during ICU stay, n (\%) } \\
\hline Neuromuscular blocking agents & 596 & (90) & 550 & (89) & 46 & (92) & 0.63 \\
\hline Nitric oxide inhalation & 209 & (31) & 188 & $(31)$ & 21 & $(42)$ & 0.099 \\
\hline Prone postition & 190 & (29) & 174 & $(28)$ & 16 & $(32)$ & 0.59 \\
\hline ECMO & 19 & (3) & 17 & (3) & 2 & (4) & 0.62 \\
\hline \multicolumn{8}{|c|}{ Non pulmonary organ failures during ICU stay, $\mathrm{n}(\%)$} \\
\hline Shock & 571 & $(86)$ & 530 & (86) & 41 & $(82)$ & 0.40 \\
\hline Hemodialysis & 227 & $(34)$ & 207 & $(34)$ & 20 & (40) & 0.65 \\
\hline Corticosteroid therapy & 134 & (20) & 92 & $(15)$ & 42 & $(84)$ & $<0.0001$ \\
\hline
\end{tabular}

Continuous variables are reported as median [interquartile range IQR 25-75]. Categorical variables are reported as number (percentages); ARDS, acute respiratory distress syndrome; ICU, intensive care unit; MV, mechanical ventilation; ECMO, extra-corporeal membrane oxygenation; ${ }^{\text {a }}$ Time between the worsening of respiratory symptoms and hospital admission, as mentioned in the Berlin definition; ${ }^{\mathrm{b}}$ Extra-pulmonary symptoms: cutaneous (skin rash, purpura), rheumatologic (arthralgia, arthritis, Raynaud's syndrome, myalgia), neurological, gastro-intestinal (abdominal pain, gastrointestinal bleeding), ENT (dysphonia, nasal crusts), lymphadenopathy, abnormal urinary sediment (proteinuria, hematuria); ${ }^{\mathrm{c}}$ The lowest value within 48 hours of invasive mechanical ventilation; ${ }^{\mathrm{d}}$ Based on the lowest value of $\mathrm{PaO}_{2} / \mathrm{FiO}_{2}$ ratio obtained within 48 hours of invasive mechanical ventilation, 
Table 2. Etiologies of ARDS with no common risk factors of the Berlin definition ( $n=50)$.

\begin{tabular}{|c|c|}
\hline Immune ARDS $^{\text {a }}$ & $n=18(36 \%)$ \\
\hline Connective tissue diseases & 11 \\
\hline Polymyositis & 3 \\
\hline Systemic lupus erythematosus & 3 \\
\hline Rheumatoid arthritis & 2 \\
\hline Scleroderma & 2 \\
\hline Undifferentiated connective tissue disease & 1 \\
\hline Small-vessel vasculitides & 6 \\
\hline Granulomatosis with polyangiitis & 3 \\
\hline Microscopic polyangiitis & 1 \\
\hline Henoch-Shönlein purpura & 1 \\
\hline Mixed cryoglobulinemia & 1 \\
\hline Hypersensitivity pneumonitis & 1 \\
\hline Drug-associated ARDS & $n=13(26 \%)$ \\
\hline Chemotherapy $^{\mathrm{b}}$ & 8 \\
\hline Bleomycine & 2 \\
\hline Gemcitabine & 2 \\
\hline Docetaxel & 1 \\
\hline Anthracycline & 1 \\
\hline Lenalidomide & 1 \\
\hline Stem cell transplant & 1 \\
\hline Amiodarone & 3 \\
\hline Others & 2 \\
\hline Erlotinib & 1 \\
\hline Anti-thymocyte globulin & 1 \\
\hline Malignant ARDS & $n=7(14 \%)$ \\
\hline Malignant hemopathies & 3 \\
\hline Intravascular lymphomatosis & 1 \\
\hline T-cell lymphoma & 1 \\
\hline B-cell lymphoma - Hemophagocytic & 1 \\
\hline lymphohistiocytosis & 1 \\
\hline Lymphangitic carcinomatosis & 3 \\
\hline Adenocarcinoma in situ & 1 \\
\hline Idiopathic ARDS & $\mathrm{n}=12(24 \%)$ \\
\hline No pathological examination & 9 \\
\hline Organizing pneumonia & 2 \\
\hline Diffuse alveolar damage & 1 \\
\hline
\end{tabular}

${ }^{\text {a }}$ Including 4 patients with a previously known auto-immune disease, but no known lung involvement; ${ }^{\mathrm{b}}$ Including 2 patients with previously known lung metastases from solid tumors (pancreas, testicular), 2 patients with known hematologic malignancy (leukaemia, myeloma), and 4 patients with known solid tumor without lung metastases. 
Table 3. Characteristics of ARDS patients with no common risk factors of the Berlin definition $(n=50)$.

\begin{tabular}{|c|c|c|c|c|c|c|c|}
\hline & \multicolumn{2}{|c|}{$\underset{(\mathbf{n}=50)}{\text { All }}$} & \multicolumn{2}{|c|}{$\begin{array}{c}\text { Non- } \\
\text { survivors } \\
(\mathbf{n}=\mathbf{3 3}) \\
\end{array}$} & \multicolumn{2}{|c|}{$\begin{array}{c}\text { Survivors } \\
(\mathbf{n}=17)\end{array}$} & $\mathbf{P}$ \\
\hline \multicolumn{8}{|l|}{ Etiological subgroup, $\mathbf{n}(\%)$} \\
\hline Immune ARDS & 18 & (36) & 9 & $(27)$ & 9 & $(53)$ & 0.12 \\
\hline Drug-induced ARDS & 13 & (26) & 9 & (27) & 4 & (23) & $>0.99$ \\
\hline Malignant ARDS & 7 & $(54)$ & 6 & (18) & 1 & $(6)$ & 0.40 \\
\hline Idiopathic ARDS & 12 & $(24)$ & 9 & $(27)$ & 3 & $(18)$ & 0.51 \\
\hline \multicolumn{8}{|l|}{ Clinical presentation upon ICU admission } \\
\hline Age, years & 65 & {$[50-75]$} & 68 & [53-76] & 64 & [45-69] & 0.13 \\
\hline Male gender, $\mathrm{n}(\%)$ & 37 & $(70)$ & 24 & $(74)$ & 13 & $(66)$ & $>0.99$ \\
\hline Time from first respiratory symptoms to admission, days & 13 & {$[4-30]$} & 15 & {$[4-30]$} & 9 & {$[3-21]$} & 0.22 \\
\hline $\begin{array}{l}\text { Time from worsening of respiratory symptoms to } \\
\text { admission, days }\end{array}$ & 2 & {$[2-4]$} & 2 & [2-4] & 2 & [2-4] & 0.83 \\
\hline Extra-pulmonary symptoms, $\mathrm{n}(\%)^{\mathrm{a}}$ & 22 & (39) & 16 & $(47)$ & 6 & $(31)$ & 0.655 \\
\hline \multicolumn{8}{|c|}{ Laboratory and Imaging features within 48 hours of ICU admission } \\
\hline Bronchoalveolar lavage (BAL) fluid cytology, n & & 45 & & 30 & & 15 & \\
\hline Hemorrhagic, n (\%) & 9 & (20) & 2 & (7) & 7 & $(47)$ & 0.003 \\
\hline Total cell count, $10^{3} / \mathrm{mL}$ & 226 & {$[100-462]$} & 210 & {$[100-420]$} & 450 & {$[100-520]$} & 0.42 \\
\hline Macrophages, $\%$ & 33 & {$[18-52]$} & 35 & [24-61] & 14 & {$[10-30]$} & 0.016 \\
\hline Neutrophils, \% & 25 & {$[9-47]$} & 25 & {$[15-53]$} & 4 & {$[0-34]$} & 0.02 \\
\hline Lymphocytes, \% & 17 & {$[5-45]$} & 12 & {$[5-36]$} & 66 & [11-87] & 0.04 \\
\hline Chest CT scan patterns, $n$ & \multicolumn{2}{|r|}{41} & \multicolumn{2}{|r|}{28} & \multicolumn{2}{|r|}{13} & \\
\hline Ground glass opacities, n (\%) & 36 & (88) & 24 & $(86)$ & 12 & $(70)$ & 0.35 \\
\hline Alveolar consolidations, n (\%) & 35 & $(85)$ & 23 & $(82)$ & 12 & (92) & 0.64 \\
\hline Fibrosis, $\mathrm{n}(\%)^{\mathrm{b}}$ & 15 & (36) & 12 & $(43)$ & 3 & $(23)$ & 0.11 \\
\hline Mediastinal lymphadenopathy, n (\%) & 11 & $(27)$ & 7 & $(25)$ & 4 & $(31)$ & 0.72 \\
\hline BAL fluid cytology or CT scan patterns, $n$ & \multicolumn{2}{|r|}{47} & \multicolumn{2}{|r|}{31} & \multicolumn{2}{|r|}{16} & \\
\hline Potentially reversible lung lesions, $\mathrm{n}(\%)^{\mathrm{c}}$ & 19 & $(42)$ & 8 & $(26)$ & 11 & $(69)$ & 0.011 \\
\hline Auto-immunity tests & \multicolumn{2}{|r|}{45} & \multicolumn{2}{|r|}{28} & \multicolumn{2}{|r|}{16} & \\
\hline Presence of positive immunity tests, $\mathrm{n}(\%)$ & 18 & (40) & 10 & (36) & 8 & $(50)$ & 0.52 \\
\hline ANCA (> 20UI, $\mathrm{n}(\%))$ & 4 & (9) & 0 & $(0)$ & 4 & $(25)$ & 0.013 \\
\hline \multicolumn{8}{|l|}{ Severity criteria within 48 hours of ICU admission } \\
\hline SAPS II & 40 & [30-53] & 39 & [28-54] & 41 & [32-53] & 0.82 \\
\hline LOD score & 4 & {$[3-8]$} & 4 & {$[1-6]$} & 6 & {$[4-8]$} & 0.02 \\
\hline Shock & 22 & (44) & 16 & $(48)$ & 6 & $(35)$ & 0.55 \\
\hline Plasma creatinine level > $140 \mu \mathrm{mol} / \mathrm{L}$ & 14 & (28) & 5 & $(15)$ & 9 & (53) & 0.008 \\
\hline Non-invasive mechanical ventilation, $\mathrm{n}(\%)$ & 23 & (46) & 19 & $(57)$ & 4 & (23) & 0.035 \\
\hline Invasive mechanical ventilation, $\mathrm{n}(\%)$ & 36 & (72) & 22 & (67) & 14 & $(82)$ & 0.33 \\
\hline $\mathrm{PaO}_{2} / \mathrm{FiO}_{2}, \mathrm{mmHg}$ & 132 & [95-194] & 137 & [91-208] & 121 & [97-177] & 0.52 \\
\hline \multicolumn{8}{|l|}{ Berlin classification of ARDS, $\mathrm{n}(\%)$} \\
\hline Mild & 15 & $(30)$ & 12 & $(36)$ & 3 & $(18)$ & 0.21 \\
\hline Moderate & 13 & (26) & 6 & $(18)$ & 7 & (41) & 0.10 \\
\hline Severe & 22 & $(44)$ & 15 & $(45)$ & 7 & $(41)$ & $>0.99$ \\
\hline \multicolumn{8}{|l|}{ Outcome variables } \\
\hline Time to Invasive mechanical ventilation, days & 1 & {$[0-3]$} & 2 & {$[0-5]$} & 0 & {$[0-1]$} & 0.073 \\
\hline Duration of mechanical ventilation, days & 12 & {$[7-20]$} & 12 & {$[5-18]$} & 12 & {$[7-25]$} & 0.60 \\
\hline Ventilator-associated pneumonia, n (\%) & 21 & $(42)$ & 15 & $(45)$ & 6 & $(35)$ & 0.56 \\
\hline \multicolumn{8}{|l|}{ Rescue maneuvers during ICU stay, n (\%) } \\
\hline Neuromuscular blocking agents & 47 & (68) & 30 & (91) & 16 & (94) & $>0.99$ \\
\hline
\end{tabular}


Nitric oxide inhalation

Prone position

ECMO

Non-pulmonary organ failures during ICU stay, n (\%)

Shock

Hemodialysis

Treatment

Initiation of corticosteroids, $\mathrm{n}(\%)$

Duration of MV before corticosteroids initiation, days

Cyclophosphamide treatment, $\mathrm{n}(\%)$

$\mathrm{MV}$, mechanical ventilation; ${ }^{\mathrm{a}}$ Cutaneous (skin rash, purpura), rheumatologic (arthralgia, arthritis, Raynaud's syndrome, myalgia), neurological (localizing sign), gastro-intestinal (abdominal pain, gastrointestinal bleeding), ENT (dysphonia, nasal crusts), lymphadenopathy, abnormal urinary sediment (proteinuria, hematuria); ${ }^{\mathrm{b}}$ Lung distortion, or bronchiectasis, or honeycombing; ${ }^{\mathrm{c}}$ As assessed by three experts blinded to outcome, based on BAL fluid cytology and chest CT scan patterns. 
Table 4. Factors recorded during the first 48 hours of ICU admission and associated with ICU mortality of ARDS patients with no common risk factors of the Berlin definition $(n=50)$.

\begin{tabular}{|c|c|c|c|c|c|c|}
\hline & \multirow{2}{*}{$\mathbf{N}$} & \multirow{2}{*}{$\begin{array}{l}\text { Death } \\
\text { n }(\%)\end{array}$} & \multicolumn{2}{|c|}{ Univariate analysis } & \multicolumn{2}{|c|}{ Multivariable analysis } \\
\hline & & & OR $(95 \% \mathrm{CI})$ & $\mathrm{P}$ & aOR $(95 \% \mathrm{CI})$ & $\mathrm{P}$ \\
\hline $\begin{array}{c}\text { Non-invasive mechanical ventilation } \\
\text { Yes } \\
\text { No }\end{array}$ & $\begin{array}{l}23 \\
27\end{array}$ & $\begin{array}{l}19(83) \\
14(52)\end{array}$ & $\begin{array}{c}4.41[1.18-16.45] \\
1\end{array}$ & 0.03 & - & - \\
\hline $\begin{array}{l}\text { Presence of potentially reversible lung } \\
\text { lesions }{ }^{\text {a }} \\
\qquad \begin{array}{c}\text { Yes } \\
\text { No }\end{array}\end{array}$ & $\begin{array}{l}19 \\
28\end{array}$ & $\begin{array}{l}8(42) \\
23(82)\end{array}$ & $\begin{array}{c}0.16[0.04-0.60] \\
1\end{array}$ & 0.007 & $0.14[0.03-0.62]$ & 0.010 \\
\hline $\begin{array}{l}\text { Plasma creatinine level }>140 \mu \mathrm{mol} / \mathrm{L} \\
\qquad \begin{array}{c}\text { Yes } \\
\text { No }\end{array}\end{array}$ & $\begin{array}{l}14 \\
36\end{array}$ & $\begin{array}{l}5(36) \\
28(78)\end{array}$ & $\begin{array}{c}0.16[0.04-0.61] \\
1\end{array}$ & 0.007 & $0.13[0.02-0.65]$ & 0.013 \\
\hline LOD score & 50 & - & $0.83[0.68-1.01]$ & 0.06 & - & - \\
\hline
\end{tabular}

a As assessed by three experts blinded to outcome, based on BAL fluid cytology and chest CT scan patterns. The Hosmer-Lemeshow goodness of fit test showed good calibration of the model $(\mathrm{p}=0.95)$. 